\title{
Coexistence of a generalist owl with its intraguild predator: distance-sensitive or habitat-mediated avoidance?
}

\author{
FABRIZIO SERGIO*, LUIGI MARCHESI†, PAOLO PEDRINI† \& VINCENZO PENTERIANI* \\ *Estación Bioló gica de Doñana, Sevilla \\ Trento Natural History Museum, Trento
}

\begin{abstract}
Intraguild predation is increasingly reported as a population-limiting factor for vertebrate predators. However, long-term coexistence of the intraguild prey with its predator is a common occurrence usually maintained by some form of predator avoidance, which may be achieved through distance-sensitive avoidance (selection of sites as far as possible from the intraguild predator), and/or habitat-mediated avoidance (avoidance of habitats associated with high predation risk). The former is expected when the distribution of the predator is heterogeneous, leaving gaps which can be exploited by the prey, while the latter is expected at high predator densities, when few predation refugia are available. To date, few studies have focused on such switch in predator avoidance under changing scenarios of intraguild predator density. To test this hypothesis, we censused tawny owls (Strix aluco, body mass $\mathbf{w} 0.4 \mathrm{e} 0.7 \mathrm{~kg}$ ) and their intraguild predator, the eagle owl (Bubo bubo, w1.5e $4 \mathrm{~kg}$ ), in 12 areas of the Alps. As predicted, tawny owls were indifferent to predator distance in an area of low predation risk, they switched to distance-sensitive avoidance in an area of medium predator density and to habitat-mediated avoidance in an area of high predator density with few available refugia. Actual predation rates were low, but increased with proximity to the intraguild predator nest. Similarly, tawny owl breeding output declined with closeness to an eagle owl nest. Habitat loss associated with predator avoidance translated into population effects, leading to a negative relationship between the densities of the two owl species. The spatial gaps in tawny owl distribution caused by eagle owls indirectly favoured other owl species, resulting in higher diversity of the overall owl community and suggesting that eagle owls acted as keystone predators. Our results suggest that intraguild predation may alter habitat choices and affect density, productivity and guild structure of vertebrate mesopredators. Such effects are probably more common than previously thought.
\end{abstract}

Keywords: Bubo bubo; competition; eagle owl; interactions; predation refugia; Strix aluco; tawny owl

Intraguild predation, the killing by a predator of species that use similar resources and are thus potential competitors, has been reported as ubiquitous in terrestrial and aquatic food webs (Polis \& Holt 1992). Increasing evidence suggests that intraguild predation may affect the

Correspondence: F. Sergio, Department of Conservation Biology, Estación Biológica de Doñana, C.S.I.C., Avda. de María Luisa s/n., Pabellón del Perú, Apdo 1056, 41013 Seville, Spain (email: fsergio@ ebd.csic.es). L. Marchesi and P. Pedrini are at the Raptor Conservation Research Unit, Trento Natural History Museum, via Calepina 14, 38100 Trento, Italy. distribution and limit the populations of top predatory species, including such diverse taxa as arthropods, carnivores, birds of prey, fish and amphibians (e.g. Huang \& Sih 1991; Hileman \& Brodie 1994; Creel et al. 2001; Petty et al. 2003), with pronounced repercussions on guild structure and community diversity and stability (review in Polis et al. 1989).

In vertebrates, intraguild predation systems are usually asymmetrical and size based, with a larger, dominant species (intraguild predator or killer) preying on a smaller one (intraguild prey or victim) (Polis \& Holt 1992; Palomares \& Caro 1999). Usually, the much greater body 
size or harming potential of the killer species prevents the evolution by the prey of antipredator defences (characteristics of prey that reduce the probability of predation once the prey is in the perceptual field of the predator; Hileman \& Brodie 1994), so that coexistence is favoured by some form of predator avoidance, that is any mechanism that lowers the probability that the prey occupies the foraging microhabitat of the predator (Hileman \& Brodie 1994). Predator avoidance can be attained in three main ways: (1) temporal segregation: the intraguild prey alters its activity times so as to avoid those of the intraguild predator, a mechanism generally regarded as unsuccessful (e.g. Jaksic 1982; Fedriani et al. 1999); (2) distance-sensitive avoidance: independently of habitat, the intraguild prey selects sites as far as possible from the intraguild killer, exploiting discontinuities in the distribution of the predator (Kostrzewa 1991; Palomares et al. 1996; Durant 1998). Such predation refugia are usually dependent on landscape heterogeneity and predator density (Durant 1998; Sergio et al. 2003a); (3) habitat-mediated avoidance: the intraguild prey avoids habitats associated with high predation risk, such as those preferred by the intraguild killer (e.g. Fedriani et al. 2000).

Overall, predator avoidance must be a frequent and effective mechanism in intraguild predation systems, because long-term coexistence of the intraguild prey with its killer species has been frequently reported (Holt \& Polis 1997). However, despite its importance, there have been relatively few studies focusing on predator avoidance in vertebrate intraguild predation systems and most of them were conducted on mammals. Despite the enormous amount of research dedicated to birds of prey, surprisingly few studies were conducted on this group (Kostrzewa 1991; Hakkarainen \& Korpimäki 1996; Sergio et al. 2003a; Sunde 2005), and none of them discriminated between different forms of predator avoidance. Here, we show that the tactic used by tawny owls, Strix aluco, to avoid their intraguild predator, the eagle owl, Bubo bubo, depends on the type of resource overlap between the two species and the density of the killer, which dictates the amount of locally available enemy-free space.

The eagle owl, the largest owl in the world (body mass $\mathrm{w} 1.5 \mathrm{e} 4 \mathrm{~kg}$ ), is a food and habitat generalist frequently reported to prey on other raptor species (Mikkola 1976, 1983). It is a sit-and-wait predator typically foraging in open habitats or at the edge of woodland (Penteriani 1996). In the Alps, eagle owls prefer low-elevation open areas and wetlands, and their diet is dominated by rats, hedgehogs and edible dormice, Glis glis (Marchesi et al. 2002a; Sergio et al. 2004a). The latter arboreal mammal is typically snatched from the top of the tree canopy (L. Marchesi \& F. Sergio, personal observation). Previous analyses have shown that eagle owls can limit the populations of other raptors (Sergio et al 2003a, 2004b; Busche et al. 2004).

The tawny owl is a medium-sized $(0.4 \mathrm{e} 0.7 \mathrm{~kg})$ generalist predator, usually hunting through a sit-and-wait tactic within woodland or at its margin (Galeotti 2001). In the Alps, it shows wide flexibility in habitat use, nesting on cliffs, trees and buildings and occupying all the available woodland types at almost any elevation, with a diet dominated by edible dormice, and by woodland mice and voles (Marchesi et al. 2006). Its characteristic and persistent territorial call makes it a potentially easy prey for a nocturnal predator foraging by auditory cues such as the eagle owl.

Based on the above, tawny owls may be expected to be vulnerable to eagle owl predation in three main circumstances: (1) during territorial advertisement near their nest; (2) when foraging at the edge between woodland and open areas; and (3) when foraging in habitats preferred by dormice (the main prey shared by the two species), where casual encounters with the intraguild killer will be more likely. Under such scenario, predation is probably best avoided by distance-sensitive nest site selection. However, this may be ineffective or unfeasible if predator density is too high and continuous, leaving too little enemy-free space. In such conditions, we may expect tawny owls to make the best of a bad job by avoiding habitats associated with high predation risk the nearer to an eagle owl nest (i.e. an interaction between habitat selection and proximity to eagle owls). Finally, tawny owls have been frequently reported to prey upon and compete with other owl species (e.g. Mikkola 1976, 1983; Nilsson 1984). Therefore, the gaps in tawny owl distribution produced by eagle owls could represent spatial refugia for other owl species, indirectly enhancing the diversity of the overall owl assemblage.

Based on the above, we developed the following predictions: (1) the two species show pronounced diet overlap, mainly because of one prey item, the edible dormouse; (2) the edible dormouse selects specific habitat features, where encounter rates between the two species (i.e. predation risk) are likely to be higher; (3) mechanisms to avoid the intraguild predator will vary with predator density; more specifically, we predicted a switch from indifference to distance-sensitive avoidance, to habitatmediated avoidance along a three-step gradient of increasing predator density; (4) proximity to the intraguild killer affects the breeding output of the intraguild prey; (5) at the population level, the densities of the two species are negatively correlated; and (6) the diversity of the owl assemblage increases with eagle owl abundance.

\section{METHODS}

\section{Study Areas}

Tawny owls were censused in 2002 and 2003 in three plots chosen on the basis of eagle owl abundance: (1) Mount Baldo, a $55-\mathrm{km}^{2}$ plot holding no eagle owl territories, the nearest being located $2.1 \mathrm{~km}$ from the border of the area; (2) Adige Valley, a $210-\mathrm{km}^{2}$ plot with medium eagle owl density (2 pairs $/ 100 \mathrm{~km}^{2}$ ); and (3) Noce Valley, a $250-\mathrm{km}^{2}$ plot with high eagle owl density (3 pairs $/ 100 \mathrm{~km}^{2}$ ).

All the three areas had mountain slopes covered by extensive forests interspersed with vineyards and apple orchards at lower elevation and with managed grassland at middle elevations. Cliffs, the main nesting substrate for both species, were plentiful throughout all areas. Forests were managed for timber harvest by two main silvicultural practices: coppice woodland (Matthews 1989) at lower elevation and high forest at higher elevation. In 2002 and 2003, tawny owls were censused in another nine quadrats, each of $100 \mathrm{~km}^{2}$, randomly scattered throughout the 
Trento region, to enable us to investigate the relationship between the densities of the two owl species. All the plots of this study were larger than the cutoff value of $25 \mathrm{~km}^{2}$ below which density is overestimated through an area artefact (Galeotti 2001).

\section{Field Procedures}

We censused territorial pairs between October and February, during full-night surveys, by listening to spontaneous vocalizations and by eliciting territorial calls by broadcasting conspecific vocalizations with a portable tape recorder (e.g. Redpath 1994; Jędrzejewski et al. 1996). In each study area, we plotted a network of listening stations, located 300 e500 $\mathrm{m}$ apart depending on local topography and acoustics, so as to cover the whole area. All plots were surveyed at least three times between October and February and a territory was defined as occupied if territorial calls were heard on at least two visits with more than 30 days in between. When two supposedly different territories were near to each other $(<500 \mathrm{~m})$, we used playback stimulation to trigger simultaneous territorial songs or contests, so as to double-check the simultaneous presence of two pairs and avoid double counts of the same individual at two nearby locations. Breeding output was expressed as the number of fledglings per territorial pair and was measured by listening to the persistent food-begging calls of recently fledged young in JuneeJuly (Muir 1954; Southern et al. 1954), a method commonly used in previous studies on tawny owls (e.g. Southern 1970; Wendland 1984; Jędrzejewski et al. 1996; Ranazzi et al. 2000). If no such calls were heard in at least three successive visits distanced more than 40 days apart, the pair was assumed to have failed. Actually, 33 of the 36 pairs for which we assessed breeding success (see below) were visited a minimum of 10 times (mean $1 / 411.5$, range $1 / 410$ e15) and each listening session lasted a minimum of $2 \mathrm{~h}$. All the remaining three pairs successfully fledged young and bred in very open habitats (grassland fields with scattered hedgerows), where optimal acoustics and high visibility allowed an easy acoustical and visual detection (through a torchlight) of the begging young. Therefore, we consider that our estimate of breeding output was reliable.

To assess diet composition, we collected pellets and prey remains found under nests and roost sites. Pellets and remains were pooled, so as to minimize biases associated with each method (Marchesi et al. 2002b).

Data on eagle owl distribution and diet were available as part of a long-term study (Marchesi et al. 2002a, b; Sergio et al. 2003a, 2004a, b). The distribution of territories of the goshawk, Accipiter gentilis, another potential tawny owl predator (Sunde 2005), was known in detail for the Noce study area, as part of another research project. Goshawks were absent from the other study areas. The abundance of edible dormice was estimated through point counts conducted in JuneeJuly: we plotted 150 locations, randomly chosen within any woodland habitat of the Baldo, Noce and Adige study areas, and counted the number of individuals heard vocalizing at night within $100 \mathrm{~m}$ of the observer during a listening session of $5 \mathrm{~min}$. Finally, as part of a wider study, in 2002 and 2003 we surveyed the populations of all owl species in 10 of the study areas. The additional species were the scops owl, Otus scops, pygmy owl, Glaucidium passerinum, long-eared owl, Asio otus, and Tengmalm's owl, Aegolius funereus, and each one was the subject of an intensive population investigation in each study area (e.g. Marchesi \& Sergio 2005). Censusing methods were the same as those used for tawny owls (see above) but the survey periods changed so as to coincide with each species pre-incubation period (scops owl: AprileMay; pygmy owl: MarcheMay; long-eared owl: JanuaryeMarch; Tengmalm's owl: FebruaryeMay). All species were censused during full-night surveys (i.e. territories were checked both around sunset and sunrise).

\section{Statistical and GIS Analyses}

\section{Prediction 1: diet overlap}

Dietary overlap between the two species was calculated by means of Pianka's index (Krebs 1998).

\section{Prediction 2: dormice habitat associations}

We used stepwise logistic and multiple regression (Tabachnick \& Fidell 1996) to test the effect of environmental variables on the presence/absence and number of dormice detected at each point-count location. The explanatory variables presented to the model were: date of census, elevation, slope, ruggedness index, and the percentage of the 100-m-radius circle covered by broad-leaved woodland, conifer woodland, mixed woodland, coppice woodland, high forest, and woodland dominated by each of the four main tree species in the area.

\section{Prediction 3: predator avoidance mechanisms}

We used logistic regression to discriminate between tawny owl territories and an equal number of random locations on the basis of intraguild predation risk. We built three models, one for each of the predation risk scenario (low, medium and high eagle owl density). When a tawny owl pair used different nest sites in the 2 years of study, we randomly selected one of them for analysis. When no nest was available because no breeding took place, we used the territory barycentre, calculated as the geometric centre of the locations of: (1) daytime roost sites and (2) perches used for territorial advertisement. We then moved such territory barycentre to the nearest potentially suitable nest site (e.g. a large-enough cavity high on a tree, cliff or building).

Random locations were generated by means of the extension 'Animal Movement' of the GIS software ArcView (Hooge \& Eichenlaub 1997) and then moved to the nearest site considered as potentially suitable for tawny owls during ground surveys through a matched procedure. For example, if in an area $20 \%$ of the tawny owl nests were on trees and $80 \%$ on cliffs, we enforced that $20 \%$ and $80 \%$ of the random locations would be on trees and cliffs. Furthermore, because tawny owls are territorial and solitary nesters, the minimum nearest neighbour 
distance (NND) among random locations was set to be the same as the minimum NND among owl territories. Finally, random locations were only plotted in the same range of elevations recorded for owl territories in each area. To control for the confounding effect of habitat quality, we added to the set of explanatory variables all those considered as potentially biologically important for tawny owls (Appendix). These were measured in the field, by accessing GIS landuse maps (C.E.C. 1993; Servizio Foreste 1999) or by digitizing 1-m-resolution, aerial colour photographs (courtesy of Provincia Autonoma di Trento) and were chosen so as to measure: (1) the characteristics of the nest site and its immediate surroundings; (2) the distance to potential hunting grounds or to sources of human disturbance; and (3) the structure and composition of the landscape within $330 \mathrm{~m}$ of the nest, which is roughly half the nearest neighbour distance (NND) in our populations.

To test the hypothesis of habitat-mediated predator avoidance, we added to the explanatory variables the interaction term between proximity to an eagle owl nest and the habitat features selected by dormice. Similarly, because use of edges could increase the chance of predation, we added as an explanatory variable the interaction between proximity to an eagle owl nest and edge length.

To reduce collinearity and the number of variables presented to logistic models, we used the method of variable reduction proposed by Green (1979) and commonly used in habitat selection studies (e.g. Sergio et al. 2004a, b, c and references therein). In this method, pairs of intercorrelated variables $(r>0.6)$ are considered as estimates of a single underlying factor. Only the one likely to be perceived as more important by the study organism is retained for analysis. Of the remaining variables, only those for which high univariate differences $(\mathrm{P}<0.1)$ were detected between nest sites and random locations were included in multivariate analyses.

\section{Prediction 4: effect on breeding output}

We used multiple regression to test the effect of proximity to an eagle owl nest and environmental variables on the mean number of young fledged within each territory during the 2 years of research ( $\mathrm{N}^{1 / 4} 36$ territories). The sample size was too low to build a different model for each study area, so data were pooled and an 'area' dummy variable was added to the explanatory variables. To further reduce the number of variables presented to the model, we only used the environmental variables which entered the logistic models above.

\section{Predictions 5 and 6: population and community effects}

We used the Spearman correlation coefficient (Sokal \& Rohlf 1981) to test the relationship between (1) the densities of the two species in the 12 study areas and (2) the densities of the two species and the diversity of the owl assemblage in 10 of the study areas. Diversity was measured as the ShannoneWiener diversity index (Krebs 1998). We also related tawny owl abundance to the availability of spatial refugia, calculated as the percentage of area farther than $3 \mathrm{~km}$ from an eagle owl territory in each study plot (previous observational and telemetry data have shown that eagle owl foraging effort and predation pressure peak within $2 \mathbf{e} 3 \mathrm{~km}$ of the nest, Penteriani 1996; Sergio et al. 2003a and references therein; and unpublished radio-tracking data).

In all analyses, logistic and multiple regression models were run through a generalized linear model procedure (GLM, software GLIM 4), following Crawley (1993): all explanatory variables were fitted to the model, extracted one at a time from such maximal model and the associated change in model deviance assessed by an F test for multiple regression (GLM model with normal errors and an identity link function) or a chi-square test for logistic regression (GLM model with binomial errors and a logit link function). In all analyses, each tawny owl territory is used only once to avoid pseudoreplication. The sequential Bonferroni correction was applied as appropriate to multiple tests on the same data set. Regularity of nest spacing was assessed by means of the G-statistic (Brown 1975), calculated as the ratio of the geometric to arithmetic mean of the squared NNDs. Values above 0.65 indicate a regular dispersion of nest sites.

\section{RESULTS}

\section{Eagle Owl Predation on Tawny Owls}

Among 978 identified eagle owl prey items, six were tawny owls (five adults and one recently fledged young). All the six eagle owl pairs involved had a tawny owl territory within $1 \mathrm{~km}$ of the nest. Furthermore, the mean distance to the nearest tawny owl territory of these six pairs was significantly lower than the mean distance of the other 32 eagle owl territories known in the region (respectively: 3412 T $478 \mathrm{~m}$ and $471 \mathrm{~T} 111 \mathrm{~m}, \mathrm{t} 1 / 4-6.89$, $\mathrm{P} 1 / 40.0005)$. Therefore, proximity to eagle owls represented a risk of direct predation for adults and fledglings.

\section{Prediction 1: Diet Overlap}

Diet overlap was $97.2 \%$ by mass ( $96.2 \%$ by number) when grouping prey items by class, $27.3 \%$ (43.4\%) when grouping them by the main prey categories of Table 1 , and $21.7 \%$ (32.5\%) when classifying them at the species level. As expected, overlap was caused almost exclusively by one shared prey item, the edible dormouse (Table 1).

\section{Prediction 2: Edible Dormouse Habitat Associations}

The mean number of dormice recorded per point-count station was 1.17 T 0.18 (range $0 \mathbf{e} 5$ ). No dormice were recorded at 30 of the 150 stations. The percentage of coppice woodland within $100 \mathrm{~m}$ of each point-count location was the only variable to enter a stepwise logistic regression with dormouse presence/absence as the dependent variable (B $1 / 41.81$ T $0.64, \quad \mathrm{C}^{2} 1 / 48.00, \quad \mathrm{P}<0.01 ; \%$ correctly reclassified cases $1 / 482.6 \%$ ). Coppice woodland 
Table 1. Diet composition of tawny owls and eagle owls in the Italian Alps

\begin{tabular}{|c|c|c|c|c|}
\hline \multirow[b]{2}{*}{ Prey group } & \multicolumn{2}{|c|}{ Tawny owl (n1/4731) } & \multicolumn{2}{|c|}{ Eagle owl (n¹/4995) } \\
\hline & No. of prey (\%) & $\%$ by Mass & No. of prey (\%) & $\%$ by Mass \\
\hline Mammals & $583(79.8)$ & 88.1 & $663(66.6)$ & 71.4 \\
\hline Western hedgehog, Erinaceus europaeus & $0(0.0)$ & 0.0 & $113(11.4)$ & 25.7 \\
\hline Bank vole, Clethrionomys glareolus & $89(12.2)$ & 7.3 & $0(0.0)$ & 0.0 \\
\hline Apodemus spp. & $238(32.6)$ & 14.5 & $17(1.7)$ & 0.1 \\
\hline Brown rat, Rattus norvegicus & $0(0.0)$ & 0.0 & $223(22.4)$ & 25.2 \\
\hline Microtinae & $51(7.0)$ & 4.2 & $6(0.6)$ & 0.0 \\
\hline Edible dormouse, Glis glis & $130(17.8)$ & 53.5 & $223(22.4)$ & 8.5 \\
\hline Common dormouse, Muscardinus avellanarius & $37(5.1)$ & 2.5 & $1(0.1)$ & 0.0 \\
\hline Other mammals & $38(5.2)$ & 6.0 & $76(7.6)$ & 11.7 \\
\hline Birds & $96(13.1)$ & 11.8 & $306(30.8)$ & 27.8 \\
\hline Turdidae & $14(1.9)$ & 4.6 & $92(9.2)$ & 2.7 \\
\hline Galliformes & $0(0.0)$ & 0.0 & $17(1.7)$ & 7.3 \\
\hline Columbidae & $0(0.0)$ & 0.0 & $52(5.3)$ & 4.1 \\
\hline Other birds & $82(11.2)$ & 7.2 & $145(14.6)$ & 13.7 \\
\hline Fish & $0(0.0)$ & 0.0 & $9(0.9)$ & 0.8 \\
\hline Invertebrates & $52(7.1)$ & 0.1 & $17(1.7)$ & 0.0 \\
\hline
\end{tabular}

Tawny owl prey items were collected during 2002e2004. Eagle owl items were collected during 1993e2004. Prey were grouped by class and within main prey categories according to Marchesi et al. (2002a, b, 2006). For ease of presentation, only main prey categories accounting for at least $5 \%$ of the total in at least one of the cells are shown.

was also the only variable to enter a stepwise multiple regression with dormouse abundance as the dependent variable (B $1 / 40.41$ T $0.12, \quad \mathrm{~F}^{1 / 4} 11.3, \quad \mathrm{P}<0.002$, \% deviance explained $1 / 471.1 \%$ ). Therefore, in the following logistic models, we added to the list of explanatory variables the interaction term between proximity to an eagle owl nest and coppice woodland.

\section{Prediction 3: Predator Avoidance Mechanisms}

The availability of spatial refugia declined along the three-step gradient of increasing predation risk (Table 2): the regularity of nest dispersion declined in parallel, suggesting progressive clumping of tawny owl nest sites in the available enemy-free space (Table 2).

Table 2. Logistic regression generalized linear models discriminating between tawny owl territories and random locations in three plots (Baldo, Adige and Noce plots, central-eastern Italian Alps) with increasing densities of an intraguild predator, the eagle owl

\begin{tabular}{|c|c|c|c|c|c|c|c|}
\hline Variable & $\begin{array}{l}\text { Eagle owl } \\
\text { density* }\end{array}$ & $\begin{array}{l}\% \text { Spatial } \\
\text { refugiay }\end{array}$ & G-testz & $\begin{array}{c}\text { Parameter } \\
\text { estimateTSE }\end{array}$ & $c^{2}$ & $P$ & $\begin{array}{l}\% \text { Correctly } \\
\text { reclassified cases }\end{array}$ \\
\hline \multicolumn{8}{|l|}{ Plot } \\
\hline $\begin{array}{l}\text { a. Low predation risk } \\
\text { Distance to cliffx } \\
\text { Interspersion Indexx } \\
\text { Constant }\end{array}$ & 0 & $81 \%$ & 0.69 & $\begin{array}{r}-0.16 \mathrm{~T} 0.05 \\
0.20 \mathrm{~T} 0.09 \\
1.86 \mathrm{~T} 1.05\end{array}$ & $\begin{array}{c}7.99 \\
5.12 \\
d\end{array}$ & $\begin{array}{l}<0.01 \\
<0.05 \\
\quad d\end{array}$ & 80.3 \\
\hline $\begin{array}{l}\text { b. Medium predation risk } \\
\text { Distance to eagle owlx } \\
\text { NND** } \\
\text { Interspersion Index } \\
\text { Constant }\end{array}$ & 2 & $52 \%$ & 0.60 & $\begin{array}{l}0.05 T 0.01 \\
1.92 T 0.72 \\
0.27 T 0.10 \\
9.11 T 4.89\end{array}$ & $\begin{array}{l}6.65 \\
6.13 \\
7.08 \\
\mathbf{d}\end{array}$ & $\begin{array}{l}<0.02 \\
<0.05 \\
<0.02 \\
\quad \text { d }\end{array}$ & 81.8 \\
\hline $\begin{array}{l}\text { c. High predation risk } \\
\text { Distance to eagle owlx } \\
\text { \% Coppıce woodlandyy } \\
\% \text { Coppıce×predatıon riskzz } \\
\text { Constant }\end{array}$ & 3 & $35 \%$ & 0.38 & $\begin{array}{l}0.03 T 0.01 \\
7.96 \mathrm{~T} 2.59 \\
0.20 \mathrm{~T} 0.07 \\
1.74 \mathrm{~T} 1.19\end{array}$ & $\begin{array}{c}2.58 \\
3.31 \\
5.62 \\
\text { d }\end{array}$ & $\begin{array}{l}<0.50 \\
<0.10 \\
<0.05 \\
\quad \text { d }\end{array}$ & 81.8 \\
\hline
\end{tabular}

Explanatory variables presented to the models are those listed in the Appendix and the interaction terms between (1) proximity to an eagle owl nest and \% coppice woodland and (2) proximity to an eagle owl nest and edge length.

* Number of territories $/ 100 \mathrm{~km}^{2}$.

yCumulative sum of areas farther than $3 \mathrm{~km}$ from an eagle owl nest.

zValues above 0.65 indicate a regular dispersion of nest sites (Brown 1975).

xVariable square-root transformed.

**Variable $\log _{\mathrm{e}}$-transformed.

yyVariable converted to a proportion and arcsine square-root transformed.

zzInteraction term between \% coppice woodland and distance to eagle owl. 
In the area with no eagle owls (low predation risk), tawny owls selected sites nearer to cliffs and with a higher interspersion index (Table 2). In the medium-predationrisk plot, they selected sites farther from eagle owls, nearer to other tawny owls (i.e. more clumped in spatial refugia) and with a higher interspersion index (Table 2). Finally, in the high-predation-risk plot, only the interaction term between proximity to an eagle owl nest and coppice woodland was significant (Table 2): coppice woodland (the predation-prone habitat) was preferred when far from eagle owls and avoided in their proximity (Fig. 1). Prediction 3 was supported.

\section{Prediction 4: Effect on Occupancy and Breeding Output}

Of 72 tawny owl territories checked for occupation for at least 4 years (period 2000e2003), only five were not occupied every year: all of them were within $1 \mathrm{~km}$ of an eagle owl territory. Distance to eagle owl was the only variable that entered a stepwise multiple regression with the mean number of fledglings per territory as the dependent variable (B $\left.1 / 40.37 \mathrm{~T} 0.17, \mathrm{~F}^{1} / 44.73, \mathrm{P}<0.05\right)$. Prediction 4 was supported.

\section{Prediction 5: Population Effects}

The density of tawny owls in the 12 study areas was negatively related to the density of eagle owls $\left(r_{s} 1 / 4-0.79\right.$, $\mathrm{P} 1 / 40.027$, Fig. 2a) and positively related to the availability of spatial refugia in each area $\left(r_{s} 1 / 40.73, P_{1 / 4} 0.028\right)$. As expected, increasing eagle owl density resulted in lower availability of spatial refugia $\left(\mathrm{r}_{\mathrm{s}} 1 / 4-0.91, \mathrm{P} 1 / 40.003\right)$. The latter was positively associated with the mean proximity of tawny owls to the intraguild predator $\left(\mathrm{r}_{\mathrm{s}} 1 / 40.82\right.$, $\mathrm{P} 1 / 40.012$ ), implying that higher eagle owl densities

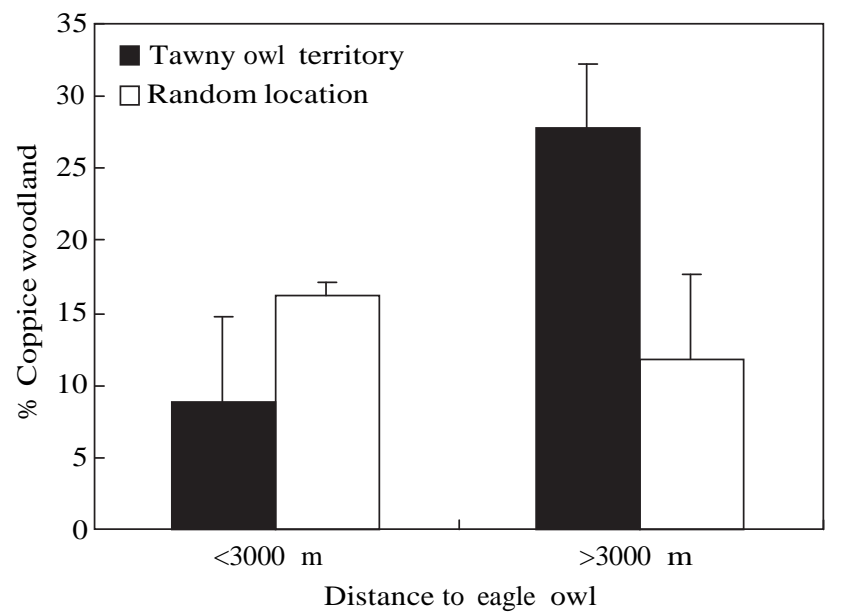

Figure 1. In the Alps, the diet of tawny owls and eagle owls overlapped extensively because of a single prey species, the edible dormouse, which was tightly associated with coppice woodland. Tawny owls avoided coppice woodland when in proximity of their potential killer and preferred it when far from eagle owls.
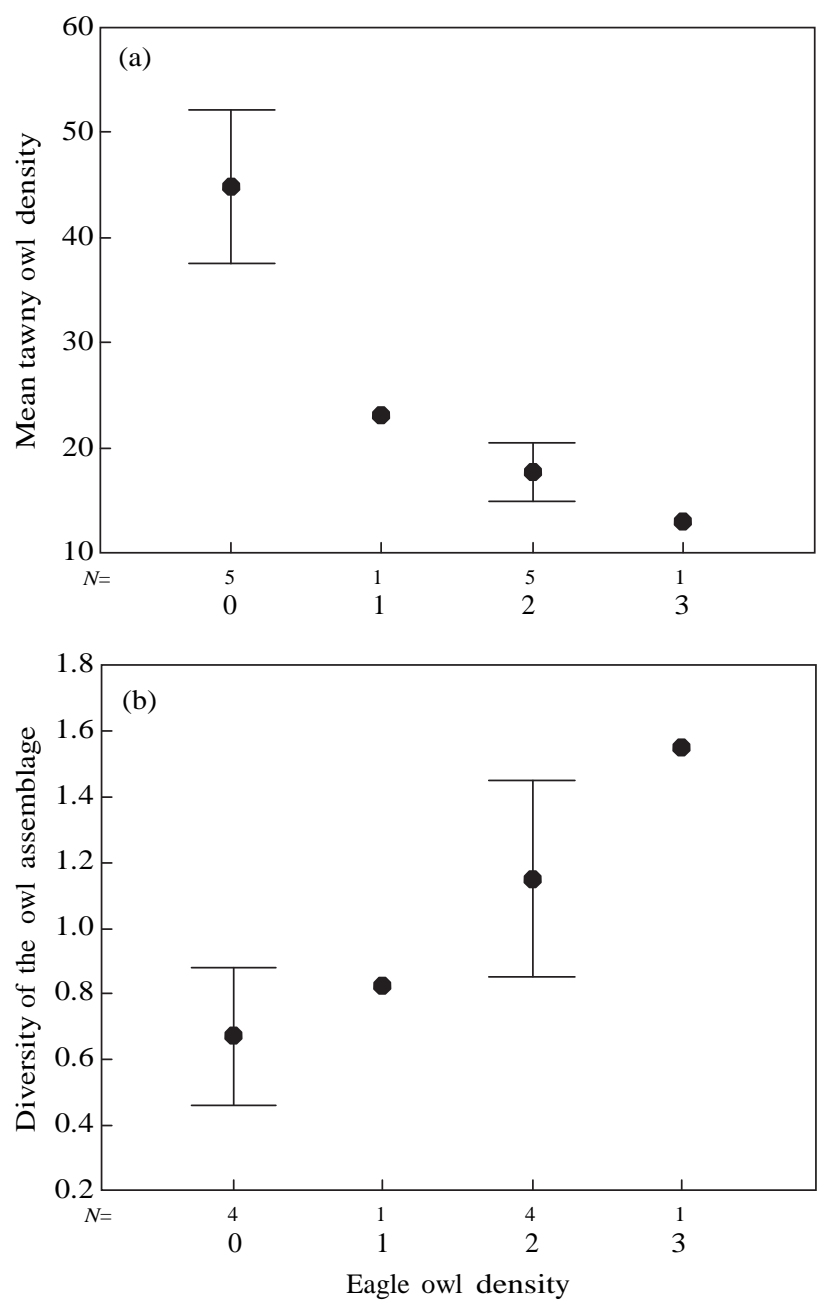

Figure 2. (a) Tawny owl density declines with increasing eagle owl density in 12 study areas of the central-eastern Italian Alps (2002e 2003). For both species, density is expressed as territories/ $100 \mathrm{~km}^{2}$. (b) The diversity of the owl assemblage increases with increasing eagle owl density.

forced tawny owls in progressively closer contact with their killer. The relationship between the regularity of tawny owl nest dispersion, as estimated by the G-statistic, and eagle owl density was not significant, albeit in the expected direction $\left(r_{s} 1 / 4-0.43, \mathrm{P}^{1 / 4} 0.16\right)$. Prediction 5 was supported.

\section{Prediction 6: Community Effects}

The diversity of the owl assemblage was negatively related to tawny owl density $\left(\mathrm{r}_{\mathrm{s}} 1 / 4-0.83\right.$, $\mathrm{n} 1 / 410$, $\mathrm{P} 1 / 40.040$ ) and positively related to eagle owl density $\left(r_{s} 1 / 40.90, n^{1 / 4} 10, P^{1 / 4} 0.030\right.$, Fig. 2b). Prediction 6 was supported.

\section{DISCUSSION}

Both young and adult tawny owls were killed by eagle owls, as reported for other areas (Mikkola 1983). Even if 
the observed predation rates were low, this does not necessarily imply the absence of a predation impact (Lima \& Dill 1990). In fact, predation rates may be low because of efficient predator avoidance or simply because recording predation events is difficult, both of them typical subthe features of intraguild predation systems (Palomares \& Caro 1999; Creel et al. 2001). In agreement with this, proximity to eagle owls had diffuse effects on most tested variables, altering habitat selection, indirectly causing habitat loss, and negatively affecting density and productivity. However, tawny owls managed to coexist with their predator in all the study areas. Furthermore, many of the censused tawny owl territories were known to us for at least 10 years, suggesting that the coexistence was not a temporary event, as confirmed on a larger scale by the widespread simultaneous occurrence of the two species in Europe.

Stable coexistence was promoted by the risk-sensitive choices operated by tawny owls. Predation risk is composed of three main components: (1) the rate of encounter with the predator; (2) the time spent vulnerable to an encounter (e.g. far from protective cover); and (3) the probability of death given an encounter (Lima \& Dill 1990). Of these components, only those that are assessable by the prey and potentially under its control can lead to efficient antipredatory tactics in evolutionary or ecological time (Harvell 1990; Lima \& Dill 1990). In our study system, component (3) was unlikely to be under control of the prey: eagle owls are sit-and-wait, ambush predators and probably capture tawny owls when these inadvertently fly or perch near to them or by cuing on the persistent food-begging calls of inexperienced fledglings. Therefore, the probability of escaping a close encounter is low for the prey. In contrast, components (1) and (2) were likely to be assessable and under control of the prey for the following reasons. First, the rate of encounters with the predator probably increased in a predictable manner the nearer to an eagle owl nest, as proved by the steep gradient of lower breeding output and higher probability of tawny owl predation events radiating from the killer nest. In turn, tawny owls were likely to know the locations of their predator territories because eagle owls frequently advertise territory ownership through long bouts of calling, audible over distances of kilometres. Secondly, given the habitat choices of the shared dormouse prey, encounter rates were likely to be high within coppice woodland. When hunting for dormice in such habitat, tawny owls probably spend much time perched and actively cuing on sounds nearby. In this scenario, they could directly estimate the potential rate of encounter in such habitat, setting the stage for habitat-mediated predator avoidance. Therefore, the major components of predation risk were potentially assessable and under control of the prey, selecting for both distance-sensitive and habitat-mediated predator avoidance.

In agreement with the above, both distance-sensitive and habitat-mediated predator avoidance were observed, but their relative importance depended on the intraguild predator density. First, in an area of low predation risk, tawny owls were neutral to proximity to eagle owls, which were always far enough away not to represent a threat.
Second, in an area of medium eagle owl density, tawny owls reduced predation risk by exploiting spatial refugia associated with heterogeneity in the distribution of the intraguild predator. However, at high eagle owl density very few refugia were available, and tawny owls coexisted with their predator, albeit at lower density, by habitatmediated avoidance, as originally predicted. Previous authors have reported a switch in site-selection tactics from indifference to active avoidance of an intraguild predator (Hileman \& Brodie 1994; Durant 1998; Sergio et al. 2003a). However, to our knowledge, this is the first study to report also a switch from distance-mediated to habitat-related avoidance, dictated by changes in the density of the intraguild predator.

It is difficult to say whether the observed avoidance patterns were voluntary active choices of the individuals or the indirect outcome of constant, selective removal by the intraguild predator. However, the two processes are likely to be interdependent because site-selection choices are usually regarded as adaptive (Clark \& Schluter 1999; Sergio et al. 2003b), and any factor consistently affecting natality and mortality, such as predation, is likely to be incorporated as a site-selection decision factor over evolutionary time (e.g. Lima \& Dill 1990). Whatever the mechanism behind it, the capability of tawny owls to alter their antipredatory tactic in relation to predation risk may further reinforce coexistence (Holt \& Polis 1997; Durant 2000). Such response flexibility is expected when the cost of gathering information about predation risk is low and when the cues used to predict predation risk are reliable (Harvell 1990). Both conditions probably apply to our system (see above).

The stable coexistence between the two owls was not at no cost for the intraguild prey. First, predator avoidance implied much habitat loss for the intraguild prey, with repercussions on density (see below). Second, productivity steeply declined with increasing proximity to eagle owls. The latter effect was probably the collective outcome of many factors, including: (1) direct predation on fledglings; (2) predation on breeding adults with consequent nesting failure; (3) less efficient habitat utilization within occupied tawny owl territories (e.g. through avoidance of prey-rich coppice woodland); and (4) individual quality, with lowerquality individuals more likely to occupy lower-quality territories near the intraguild predator (e.g. Newton 1991; Hakkarainen \& Korpimäki 1996). A further possibility is that the begging behaviour of the fledglings may have been affected by predation risk, with fledged tawny owls calling less when in proximity of eagle owl territories. However, even if we did not quantify begging rates, we had no impression that broods adjusted their begging calls in response to predation risk. Tawny owl fledglings located in proximity of eagle owl nests were frequently heard begging at high rates and, once we detected a fledged brood located near an eagle owl nest, chicks were heard begging during most subsequent visits, suggesting a rather constant level of conspicuousness. Finally, we doubt that our results could have been biased by such adjustments because the nest areas were visited a very large number of times (usually more than 10) and even the most elusive broods were contacted already at the third nest visit. 
Processes at the level of the individual translated into population consequences, with a negative relationship between the densities of the two owls. Similar negative associations have been reported for other vertebrate predators, both through time (e.g. Petty et al. 2003; Busche et al. 2004) and space (Creel et al. 2001; Sergio et al. 2003a, 2005b). Other studies have reported negative relationships between the occurrence of an intraguild predator and the breeding success of its vertebrate intraguild prey (e.g. Sergio et al. 2003a). We suggest that such population-level intraguild predation effects may be more common than previously thought, especially in 'pristine' communities where coexistence among many predators is pronounced (e.g. Caro \& Stoner 2003). They are also likely to increase in frequency in more human-altered landscapes, where populations of top vertebrate predators are often increasing or recolonizing areas from which they had been extirpated (e.g. Petty et al. 2003; Busche et al. 2004). This underlines the increasingly recognized importance of including a predation perspective in studies of so-called vertebrate 'top predators'.

Finally, a little explored area of intraguild predation in vertebrates is its potential community-level effects. In our study, the diversity of the owl assemblage declined with increasing tawny owl density and increased with eagle owl abundance. Tawny owls have been reported to prey upon, compete and limit the populations of the other owl species of this study (e.g. Mikkola 1983; Nilsson 1984; Koenig 1998). Therefore, the presence and spatial distribution of eagle owls will create gaps in tawny owl distribution, which in turn could function as spatial refugia for the other owl species, with an overall positive effect on the diversity of the whole assemblage. Such interaction could represent one of the mechanisms contributing to the previously reported link between vertebrate predators and high biodiversity value (Sergio et al. 2005a). Of course, such positive effect is to be expected only if eagle owls do not depress also the populations of the other owl species. In this sense, the eagle owl could be considered as a keystone predator (Polis et al. 1989). To our knowledge, this is the first study providing evidence, albeit correlative, that a single vertebrate species may affect the structure of a whole assemblage of vertebrate predators. Overall, such cascading effects of intraguild predation on assemblages of vertebrate predators may be more common than previously thought, considering that dynamics compatible with such processes are common in the literature: for example, in central Europe, eagle owls may limit goshawk densities (Busche et al. 2004), which in turn may limit other raptors (Kostrzewa 1991; Petty et al. 2003). In Fennoscandia, large owls prey on medium-sized owls and diurnal raptors, which in turn prey on mustelids (Korpimäki \& Norrdahl 1989; Hakkarainen \& Korpimäki 1996) and in North America wolves Canis lupus prey on coyotes Canis latrans, which in turn prey on foxes, in turn preying on mustelids (Creel et al. 2001).

\section{Intraguild Predation, Behavioural Interactions and Conservation}

Wildlife-habitat models are being increasingly used as tools for conservation. However, the spread of GIS technology has caused increasing emphasis on the land use component of the ecosystem (e.g. Sergio et al. 2004c). Our results show that analyses based only on environmental variables may yield biased information, because behavioural, interspecific interactions may alter the selected habitat features. For example, validation of our habitat model built with data from the predation-free Baldo area by applying it to the independent data from a high-density eagle owl area (e.g. Noce plot) resulted in a poor classification rate (45\% of the owl territories and $48 \%$ of the random locations). A further source of error will be the choice of random locations with which to compare occupied sites: such locations should estimate resource availability, but many of such locations will actually be unavailable to the study species because of (unmeasured) predation risk. Such biased results may be extremely widespread because most species are likely to coexist with some potential predators (e.g. Caro \& Stoner 2003). The problem is exacerbated by the frequently subtle nature of intraguild predation interactions: observed predation rates may be low (because of efficient predator avoidance), and the two species may be well separated in space because of the ghost of past interactions (e.g. Sergio et al. 2004c). In addition, predation risk radiating from a nest is often unrelated to habitat, and acts as an 'invisible gradient' overlaid on the landscape. Therefore, unless the intraguild relationship is hypothesized in advance based on in-depth knowledge of the target intraguild prey, habitat models are likely to lead to erroneous conclusions about habitat quality, thus reducing the effectiveness of conservation guidelines.

\section{Acknowledgments}

We thank W. Cresswell, M. Licantropi, M. Naguib, I. Newton, J. Valkama and an anonymous referee for comments on a previous draft of the manuscript. Part of this study was funded by 'Project Biodiversità', funded by the Autonomous Province of Trento.

\section{References}

Brown, D. 1975. A test of randomness of nest spacing. Wildfowl, 26, $102 \mathbf{e} 103$.

Busche, G., Raddatz, H. J. \& Kostrzewa, A. 2004. Nistplatz-Konkurrenz und Prädation zwischen Uhu (Bubo bubo) und Habicht (Accipiter gentilis): erste Ergebnisse aus Norddeutschland. Die Vogelwarte, 42, 169e177.

Caro, T. M. \& Stoner, C. J. 2003. The potential for interspecific competition among African carnivores. Biological Conservation, 110, 67 e75.

C.E.C. Commission of the European Communities, DirectorateGeneral e Environment, Nuclear Safety and Civil Protection. 1993. CORINE Land Cover e Guide technique. Bruxelles: Office for Official Publications of the European Communities.

Clark, R. G. \& Schluter, D. 1999. Avian habitat selection: pattern from process in nest-site use by ducks? Ecology, 80, 272e287.

Crawley, M. J. 1993. GLIM for Ecologists. Oxford: Blackwell Scientific.

Creel, S., Spong, G. \& Creel, N. 2001. Interspecific competition and the population biology of extinction-prone carnivores. 
In: Carnivore Conservation (Ed. by J. L. Gittleman, S. M. Funk, D. MacDonald \& R. K. Wayne), pp. 35e60. Cambridge: Cambridge University Press.

Durant, S. M. 1998. Competition refuges and coexistence: an example from Serengeti carnivores. Journal of Animal Ecology, 67, 370 e386.

Durant, S. M. 2000. Living with the enemy: avoidance of hyenas and lions by cheetahs in the Serengeti. Behavioral Ecology, 11, 624 e632.

Fedriani, J. M., Palomares, F. \& Delibes, M. 1999. Niche relationships among three sympatric Mediterranean carnivores. Oecologia, 121, 138 e148.

Fedriani, J. M., Fuller, T. H., Sauvajot, R. M. \& York, E. C. 2000. Competition and intraguild predation among three sympatric carnivores. Oecologia, 125, 258e270.

Galeotti, P. 2001. Strix aluco tawny owl. BWP Update, 3, 1 e34.

Green, R. H. 1979. Sampling Design and Statistical Methods for Environmental Biologists. New York: J. Wiley.

Hakkarainen, H. \& Korpimäki, E. 1996. Competitive and predatory interactions among raptors: an observational and experimental study. Ecology, 77, 1134e1142.

Harvell, C. D. 1990. The ecology and evolution of inducible defenses. Quarterly Review in Biology, 6, 232e340.

Hileman, K. S. \& Brodie, E. D. 1994. Survival strategies of the salamander Desmognathus ochrophaeus: interaction of predator avoidance and anti-predator mechanisms. Animal Behaviour, 47, 1 e6.

Holt, R. D. \& Polis, G. A. 1997. A theoretical framework for intraguild predation. American Naturalist, 149, 745e764.

Hooge, P. N. \& Eichenlaub, B. 1997. Movement. Animal Movement Extension to ArcView ver. 1.1. Anchorage: Alaska Biological Science Center, U.S. Geological Survey.

Huang, C. \& Sih, A. 1991. Experimental studies on direct and indirect interactions in a three trophic-level stream system. Oecologia, 85, 530e536.

Jaksic, F. M. 1982. Inadequacy of activity time as a niche difference: the case of diurnal and nocturnal raptors. Oecologia, 32, 172e175.

Jędrzejewski, W., Jędrzejewska, B., Szymura, A. \& Zub, K. 1996. Tawny owl (Strix aluco) predation in a pristine deciduous forest (Bialowiezza National Park, Poland). Journal of Animal Ecology, 65, 105 e120.

Koenig, C. 1998. Ecology and population of pigmy owls Glaucidium passerinum in the Black Forest (S.W. Germany). In: Holarctic Birds of Prey (Ed. by B. U. Meyburg, R. D. Chancellor \& F. F. Ferrero), pp. 447e450. Badajoz: Adenex-WWGBP.

Korpimäki, E. \& Norrdahl, K. 1989. Avian predation on mustelids in Europe 1: occurrence and effects on body size variation and life traits. Oikos, 55, 205e215.

Kostrzewa, A. 1991. Interspecific interference competition in three European raptor species. Ethology, Ecology and Evolution, 3, 127 e143.

Krebs, C. J. 1998. Ecological Methodology. New York: Harper Collins.

Lima, S. L. \& Dill, L. M. 1990. Behavioral decisions made under the risk of predation: a review and prospectus. Canadian Journal of Zoology, 68, 619e640.

Marchesi, L. \& Sergio, F. 2005. Distribution, density, diet and productivity of the scops owl Otus scops in the Italian Alps. Ibis, 147, $176 \mathrm{e} 187$.

Marchesi, L., Sergio, F. \& Pedrini, P. 2002a. Costs and benefits of breeding in human-altered landscapes for the eagle owl Bubo bubo. Ibis, 144, E164eE177.

Marchesi, L., Pedrini, P. \& Sergio, F. 2002b. Biases associated with diet study methods in the Eurasian Eagle Owl. Journal of Raptor Research, 36, 11e16.
Marchesi, L., Sergio, F. \& Pedrini, P. 2006. Implications of temporal changes in forest dynamics on density, nest-site selection, diet and productivity of tawny owls Strix aluco in the Alps. Bird Study, 53, 310e318.

Matthews, J. D. 1989. Silvicultural Systems. Oxford: Oxford University Press.

Mikkola, H. 1976. Owls killing and killed by other owls and raptors in Europe. British Birds, 69, 144e154.

Mikkola, H. 1983. Owls of Europe. Calton: T. \& A. D. Poyser.

Muir, R. C. 1954. Calling and feeding rates of fledged tawny owls. Bird Study, 1, 111e117.

Newton, I. 1991. Habitat variation and population regulation in Sparrowhawks. Ibis, 133, 76e88.

Nilsson, I. N. 1984. Prey weight, food overlap, and reproductive output of potentially competing long-eared and tawny owls. Ornis Scandinavica, 15, 176e182.

Palomares, F. \& Caro, T. M. 1999. Interspecific killing among mammalian carnivores. American Naturalist, 153, 492e508.

Palomares, F., Ferreras, P., Fedriani, J. M. \& Delibes, M. 1996. Spatial relationships between Iberian lynx and other carnivores in an area of south-western Spain. Journal of Applied Ecology, 33, 5e13.

Penteriani, V. 1996. The Eagle Owl. Bologna: Edagricole.

Petty, S. J., Anderson, D. I. K., Davison, M., Little, B., Sherratt, T. N., Thomas, C. J. \& Lambin, X. 2003. The decline of common kestrels Falco tinnunculus in a forested area of northern England: the role of predation by northern goshawks Accipiter gentiles. Ibis, 145, 472e483.

Polis, G. A. \& Holt, R. D. 1992. Intraguild predation: the dynamics of complex trophic interactions. Trends in Ecology and Evolution, 7, 151 e154

Polis, G. A., Myers, C. A. \& Holt, R. D. 1989. The ecology and evolution of intraguild predation: potential competitors that eat each other. Annual Review of Ecology and Systematics, 20, 297e330.

Ranazzi, L., Manganaro, A. \& Salvati, L. 2000. The breeding success of tawny owls (Strix aluco) in a Mediterranean area: a long-term study in urban Rome. Journal of Raptor Research, 34, 322 e326.

Redpath, S. M. 1994. Censusing tawny owls Strix aluco by the use of imitation calls. Bird Study, 41, 192e198.

Sergio, F., Marchesi, L. \& Pedrini, P. 2003a. Spatial refugia and the coexistence of a diurnal raptor with its intraguild owl predator. Journal of Animal Ecology, 72, 232e245.

Sergio, F., Pedrini, P. \& Marchesi, L. 2003b. Spatio-temporal shifts in gradients of habitat quality for an opportunist avian predator. Ecography, 26, 243e255.

Sergio, F., Marchesi, L. \& Pedrini, P. 2004a. Integrating individual habitat choices and regional distribution of a biodiversity indicator and top predator. Journal of Biogeography, 31, 619e628.

Sergio, F., Marchesi, L., Pedrini, P., Ferrer, M. \& Penteriani, V. 2004b. Electrocution alters the distribution and density of a top predator, the eagle owl Bubo bubo. Journal of Applied Ecology, 41, 836e845.

Sergio, F., Rizzolli, F., Marchesi, L. \& Pedrini, P. 2004c. The importance of interspecific interactions for breeding-site selection: peregrine falcons seek proximity to raven nests. Ecography, 27, $818 \mathbf{e} 826$

Sergio, F., Newton, I. \& Marchesi, L. 2005a. Top predators and biodiversity. Nature, 436, 192.

Sergio, F., Scandolara, C., Marchesi, L., Pedrini, P. \& Penteriani, V. 2005b. Effect of agro-forestry and landscape changes on common buzzards (Buteo buteo) in the Alps: implications for conservation. Animal Conservation, 7, 17e25.

Servizio Foreste. 1999. Carta Fisionomica della Copertura Forestale in Trentino. Trento: Provincia Autonoma di Trento. 
Sokal, R. R. \& Rohlf, F. J. 1981. Biometry. New York: W. H. Freeman.

Southern, H. N. 1970. The natural control of a population of tawny owls (Strix aluco). Journal of Zoology, 162, 197e285.

Southern, H. N., Vaughan, R. \& Muir, R. C. 1954. The behaviour of young tawny owls after fledgling. Bird Study, 1, 101e110.
Sunde, P. 2005. Predators control post-fledging mortality in tawny owls, Strix aluco. Oikos, 110, 461e472.

Tabachnick, B. G. \& Fidell, L. S. 1996. Using Multivariate Statistics. New York: Harper Collins.

Wendland, V. 1984. The influence of prey fluctuations on the breeding success of the tawny owl Strix aluco. Ibis, 126, 284e295.

\section{Appendix}

Environmental variables measured at tawny owl nests and random locations

\begin{tabular}{|c|c|}
\hline Variable & Description \\
\hline Elevation (m) & Elevation of the nest a.s.l. \\
\hline$\%$ Slope & Percentage slope within $100 \mathrm{~m}$ of the nest \\
\hline Ruggedness index & Number of contour lines crossed by two NeS and WeE transects of $660 \mathrm{~m}$ \\
\hline NND $(m)$ & Distance to the nearest tawny owl territory \\
\hline Distance to eagle owl $(\mathrm{m})$ & Distance to the nearest eagle owl territory \\
\hline Distance to goshawk (m) & Distance to the nearest goshawk territory \\
\hline Distance to cliff (m) & Distance to the nearest cliff \\
\hline Distance to tree cavity $(\mathrm{m})$ & Distance to the nearest tree with potentially suitable nesting cavities \\
\hline Distance to grassland $(\mathrm{m})$ & Distance to the nearest grassland field \\
\hline Distance to coppice (m) & Distance to the nearest coppice-managed woodlot \\
\hline Distance to high forest $(\mathrm{m})$ & Distance to the nearest patch of woodland managed as high forest \\
\hline Distance to building (m) & Distance to the nearest building \\
\hline Distance to dirt road $(\mathrm{m})$ & Distance to the nearest dirt road \\
\hline Distance to road (m) & Distance to nearest paved road \\
\hline Distance to building (m) & Distance to the nearest inhabited building Cliff \\
\hline length $(\mathrm{m})$ & Length of cliff fronts within a radius of $330 \mathrm{~m}$ \\
\hline Isolated trees & Number of isolated trees within a radius of $330 \mathrm{~m}$ \\
\hline Edge length $(\mathrm{m})$ & Length of edges between woodland and grassland \\
\hline Open interspersion index & $\begin{array}{l}\text { Number of boundaries between woodland and grassland crossed by two NeS and WeE transects of } \\
660 \mathrm{~m}\end{array}$ \\
\hline Interspersion index & Number of habitat boundaries crossed by two NeS and WeE transects of $660 \mathrm{~m}$ \\
\hline \% Coppice woodland & $\%$ Extent of coppice-managed woodland within a radius of $330 \mathrm{~m}$ \\
\hline \% Beech coppice & \% Extent of coppice-managed woodland dominated by beech within a radius of $330 \mathrm{~m}$ \\
\hline$\%$ High forest & $\%$ Extent of woodland managed as high forest within a radius of $330 \mathrm{~m}$ \\
\hline$\%$ Broad-leaved high forest & $\%$ Extent of broad-leaved high forest within a radius of $330 \mathrm{~m}$ \\
\hline$\%$ Conifer high forest & $\%$ Extent of conifer, high forest within a radius of $330 \mathrm{~m}$ \\
\hline$\%$ Broad-leaved woodland & $\%$ Extent of broad-leaved woodland within a radius of $330 \mathrm{~m}$ \\
\hline$\%$ Total woodland & \% Extent of any woodland type within a radius of $330 \mathrm{~m}$ \\
\hline$\%$ Urban areas & $\%$ Extent of urban areas within a radius of $330 \mathrm{~m}$ \\
\hline$\%$ Grassland & $\%$ Extent of grassland within a radius of $330 \mathrm{~m}$ \\
\hline$\%$ Farmland & $\%$ Extent of intensive farmland within a radius of $330 \mathrm{~m}$ \\
\hline \% Rocky & $\%$ Extent of rocky outcrops and arid-sparse vegetation within a radius of $330 \mathrm{~m}$ \\
\hline Habitat diversity & 1- Shannon index* of habitat diversity (Krebs 1998) \\
\hline
\end{tabular}

Calculated as: $S\left(p \log _{e} p\right)$, where $p$ is the proportion of each habitat type. 